www.nature.com/ejhg

\title{
Association between quantitative traits underlying asthma and the HLA-DRB1 locus in a family-based population sample
}

\author{
Miriam F Moffatt*,1, Carsten Schou ${ }^{2}$, Jennifer A Faux ${ }^{1}$, Gonçalo R Abecasis ${ }^{1}$, Alan James ${ }^{3}$, \\ A William Musk ${ }^{3}$ and William OCM Cookson ${ }^{1}$
}

${ }^{1}$ Wellcome Trust Centre for Human Genetics, Roosevelt Drive, Headington, Oxford OX3 7BN, UK; ${ }^{2} A L K-A B E L L O$ GROUP Research, Hørsholm, Denmark; ${ }^{3}$ Sir Charles Gairdner Hospital, Nedlands, Western Australia 6009

The region of human chromosome 6 containing the MHC has been identified as influencing asthma and atopy (allergy) by several genome-wide searches. The MHC contains many genes with potential effects on innate and specific immunity. As a first step in dissecting MHC influences on asthma and its underlying quantitative phenotypes, we have examined the HLA-DRB1 locus in a population sample consisting of 1004 individuals from $\mathbf{2 3 0}$ families from the rural Australian town of Busselton. The locus was strongly associated with the $\left(\log _{\mathrm{e}}\right)$ total serum IgE concentration, accounting for $4.0 \%$ of the $\sigma^{2}$ (variance) in that trait (multiallelic test, $P=0.00001$ ). The locus also influenced specific IgE titres to common allergens (multi-allelic tests, $2.8 \% \sigma^{2}$ for the house dust mite allergen Der $p \mathrm{I}, P=0.0013 ; 3.0 \%$ of $\sigma^{2}$ for Der $p \mathrm{II}, P=0.0007$; and $2.1 \%$ of $\sigma^{2}$ for the cat allergen $\mathrm{Fel} d \mathrm{I}, P=\mathbf{0 . 0 1 4}$ ). No associations were found to the categorical phenotype of asthma, or to the quantitative traits of peripheral blood eosinophil counts and bronchial hyper-responsiveness.

Transmission disequilibrium tests excluded genetic admixture as a cause of false-positive findings. The results indicate that HLA-DRB1 alleles modulate the total serum IgE concentration and IgE responses to allergens, but do not account for the previous observations of linkage of asthma to the MHC. European Journal of Human Genetics (2001) 9, $341-346$.

Keywords: HLA-DR; asthma; quantitative traits

\section{Introduction}

Allergic (atopic) asthma is the most common disease of childhood, ${ }^{1}$ and now affects 155 million individuals in the world. Asthma is highly heritable, ${ }^{2}$ and many centres are now involved in studies to discover the genetic basis of asthma susceptibility. ${ }^{3}$

The asthma phenotype is complex. Ninety per cent of children with the disease show signs of IgE mediated allergy to common inhaled proteins, known as allergens. Asthma is

${ }^{*}$ Correspondence: Dr Miriam F Moffatt, Wellcome Trust Centre for Human Genetics, University of Oxford, Roosevelt Drive, Headington, Oxford OX3 7BN, UK.

Tel: + 441865287607 / 287577; Fax: + 441865 287578;

E-mail: miriam@well.ox.ac.uk

Received 24 October 2000; revised 19 January 2001; accepted 23 January 2001 associated primarily with allergy to house dust mite (HDM) and to a lesser degree with allergy to cat dander and moulds. $^{4,5}$ Asthmatics may also exhibit elevations of the total serum IgE concentration, peripheral blood eosinophilia, and bronchial hyper-responsiveness to non-specific stimuli such as methacholine or histamine.

Segregation analyses have indicated that $\operatorname{IgE}$ titres to particular allergens only partially overlap with the genetic determinants of the total serum IgE. ${ }^{6,7}$ Analyses of linkage and association to these traits may therefore require adjustment or correction for each other, in addition to adjustments for the recognised effects of age and sex. ${ }^{6}$

A number of genome-wide searches for linkage to asthma and its associated traits have been carried out in diverse populations and show reproducible patterns of linkage. ${ }^{3,8}$ The major histocompatibility complex (MHC) 
region on chromosome 6 has shown consistent linkage to asthma-associated phenotypes in several studies $^{9-12}$ and may be considered to be a major locus influencing allergic diseases.

The MHC contains many molecules involved in innate and specific immunity. Investigation of the effects of the MHC on asthma and its related phenotypes therefore poses a considerable methodological and statistical challenge. Studies of genetic linkage may lack power to resolve this complexity. Although linkage disequilibrium (LD) extends for long distances in the MHC, LD mapping and association testing with candidate gene polymorphisms are likely to be the most effective means of dissecting out the effects of individual genes.

This present study has therefore investigated the highly polymorphic HLA-DRB1 locus for effects on asthma and its associated phenotypes. Many previous association studies with asthma-associated phenotypes and MHC alleles have suffered from small sample sizes, poor correction for multiple testing due to multiple alleles, and an inability to control for population admixture. We have therefore used a familybased population sample to control for admixture, and carried out initial analyses with multi-allelic tests of significance. The approach allowed exploration of the effects of covariates, together with estimation of the effect of alleles on phenotypic variation.

\section{Methods}

The subjects were young nuclear families from the rural coastal town of Busselton in South-Western Australia. Children under 5 years old were excluded because they could not complete respiratory testing. Families were identified through adults aged 55 years or under, from an electoral roll of approximately 9000 . Families were serially recruited until a pre-determined target of 1000 individuals was reached. The final sample consisted of 1004 subjects in 230 nuclear families.

1867 individuals were approached to achieve the final sample. One hundred and seventy-seven had refused a part in the study, 140 were not contactable, and 434, although contacted, had not been tested by the end of the study. Seven hundred and eight subjects were excluded because their spouses were older than 55 years, or because they were not married with two or more natural children over the age of 5 years. The remaining 408 individuals and their spouses and children not on the electoral roll completed the study. Subjects knew the respiratory interest of the investigation before agreeing to participate. It was emphasised that normal people were important to the study.

Testing took place in the winter months of May, June and July 1992. A respiratory questionnaire, based on the ATS questionnaire but including questions on rhinitis and allergies, was administered. Physician-diagnosed asthma was defined as a positive response to the questions 'Have you ever had an attack of asthma?' and 'If yes, has this happened on more than one occasion' and 'Has your doctor ever told you that you have asthma?'.

Skin prick testing to Dermatophagoides pteronyssinus (HDM), mixed grass pollen, cat and dog dander, Aspergillus fumigatus, Alternaria alternata and a negative control (Dome-HollisterSteir, Spokane USA)) was carried out as previously described. ${ }^{13}$ Wheal diameters were calculated minus the negative control.

Bronchial responsiveness to methacholine was measured with a maximum dose of $12 \mu \mathrm{mol}$ administered by hand-held deWilbus nebulisers. ${ }^{14}$ The slope of the dose response curve was calculated as (pre-dose forced expiratory volume in $1 \mathrm{~s}$ (FEV1) - last FEV1) divided by the final cumulative dose of methacholine. To allow $\log _{\mathrm{e}}$ transformation, negative slopes and slopes of 0 were coded as 0.001 . Blood was taken by venipuncture for IgE assays, eosinophil counts and DNA studies.

The total serum IgE was determined by ELISA (Pharmacia CAP system FEIA, Sweden). Sera were tested for elevation of IgE titres to the major allergens Der $p$ I, Der $p$ II (from the house dust mite Dermatophagoides pteronyssinus), Fel $d$ I (from the household cat Felix domesticus) and Phl p V (from timothy grass, Phleum praetense) by chemiluminescence assay using monoclonal anti-IgE (ALK Laboratories, Hørsholm, Denmark). Results were converted to RAST classes. A specific IgE RAST class $1(\geqslant 0.35 \mathrm{ku} / \mathrm{l})$ was considered positive. DNA was extracted from peripheral blood leucocytes by a standard phenol-chloroform protocol. Peripheral blood eosinophils were counted automatically by Coulter Counter (Western Diagnostic Laboratories, Western Australia), and the results $\log _{\mathrm{e}}$ converted before analyses.

HLA-DRB1* typing was by SSO probing with digoxigeninddUTP (Boehringer Mannheim) labelled probes as described previously. ${ }^{15,16}$ HLA-DR types were determined for HLADRB $1{ }^{*} 01$ up to and including * 16 . HLA-DRB $1{ }^{*} 0103$ was distinguished from all other $\mathrm{DRB} 1{ }^{\star} 01$ alleles, and HLADRB1*1501 was distinguished from all other DRB $1{ }^{*} 02$ alleles. Subtypes were recognised for HLA-DRB1*04 $\left({ }^{*} 0401-{ }^{*} 0408\right)$, HLA-DRB $1{ }^{*} 05$ (HLA-DRB $1{ }^{*} 11$ and HLADRB1*12) and for HLA-DRB1*06 (HLA-DRB1*13 and HLADRB1*14) using SSO probing following previous protocols ${ }^{15}$ but with digoxigenin-ddUTP labelled probes. Genotypes were checked independently by two individuals who were blind to the phenotype. Failed amplifications were repeated twice.

Association of all alleles with physician diagnosed asthma was sought by one-way analysis of variance (SPSS 6.1). Statistical analyses of quantitative traits were carried out by the QTDT program, which allowed variance-components testing of family-based samples for association, admixture, and transmission disequilibrium. ${ }^{17}$ To avoid multiple comparisons, multi-allelic tests were initially performed, and individual alleles were only examined if the multi-allelic tests were positive. 


\section{Results}

Five hundred and two of the 1004 individuals were male. The parents $(n=460)$ were aged $30-55$ years (mean 40.2 (SD 4.98) years) and the children $(n=544) 5-27$ years (mean $12.6(4.73)$ years).

Eighteen per cent of the population and $20 \%$ of the children were asthmatic. The $\log _{e}$ of bronchial responsiveness ( $\log _{\mathrm{e}}$ slope) was approximately normally distributed with a mean of -3.67 and a standard deviation of 1.93 . The mean was $-4.07 \pm 1.53$ in normal subjects and $-1.85 \pm 2.41$ in asthmatics.

Positive responses to the allergens Der $p$ I, Der $p$ II and Phl $p$ $\mathrm{V}$ (RAST score $\geqslant 1$ ) were seen in more than $25 \%$ of the subjects (Table 1). Approximately $14 \%$ of individuals showed reactivity to the cat allergen $\mathrm{Fel} d$ I.

The results of HLA-DRB1 typing gave similar allele frequencies whether all subjects were considered, or whether unrelated subjects (the parents) were considered (Table 2), suggesting that the population sample was balanced.

Multi-allelic tests of association were initially carried out. Physician diagnosed asthma did not show any association with the locus, and neither did bronchial responsiveness (slope) or the Log peripheral eosinophil counts.

$\log _{\mathrm{e}}$ IgE levels showed highly significant association with HLA-DRB1 alleles (Table 3). The addition of age and sex as covariates slightly improved the significance of the results and the variance $\left(\sigma^{2}\right)$ attributable to the marker. Inclusion of specific IgE titres to the four allergens as covariates led to a highly significant further increase in the significance of results, and suggested that $4.0 \%$ of $\sigma^{2}$ in the serum IgE was attributable to the marker (Table 3 ).

IgE titres to the major allergens Der $p$ I, Der $p$ II and Fel $d$ I did not show any association with HLA-DRB1 alleles (Table 3). However, inclusion of $\log _{\mathrm{e}} \operatorname{IgE}$ levels as a covariate ${ }^{18}$ revealed highly significant effects on Der $p$ I and Der $p$ II titres, which were marginally improved by the inclusion of age and sex as covariates. Fel $d$ I titres showed a significant association with HLA-DRB1 alleles, although the low frequency of Fel $d$ I reactivity in the subjects meant that the study may have had limited power to detect associations. Phl $p \mathrm{~V}$ titres were marginally associated with HLA-DRB1 alleles, although this effect disappeared when $\log _{\mathrm{e}}$ IgE levels were included as a covariate.

The significance of these results may be further corrected for the eight phenotypes which were tested, so that $\log _{e} \operatorname{IgE}$

Table 1 Percentage positive responses to major purified allergens

\begin{tabular}{ll}
\hline Allergen & Positive RAST score \% (>1) \\
\hline Der $p$ I & 27.9 \\
Der $p$ II & 25.4 \\
Fel $d$ I & 14.2 \\
Phl $p$ V & 26.4 \\
\hline
\end{tabular}

levels, and $\operatorname{Der} p$ I and Der $p$ II titres remain significantly associated with the HLA-DRB1 locus, whereas the association with Fel $d$ I becomes marginal $(P=0.1)$, and the association with $P h l p \mathrm{~V}$ becomes non-significant.

Tests of association between the total serum IgE and individual alleles showed a number of positive and negative associations (Table 4 ). The most significant of these were the association of high IgE levels and HLA-DRB1*01 and low levels with HLA-DRB1*13.

$\operatorname{Der} p$ I titres were negatively associated with HLA-DRB1*01 and positively associated with HLA-DRB1*1501 (Table 5). Der $p$ II titres showed the same associations. Fel $d$ I titres were weakly associated with HLA-DRB1*0401.

Eighty per cent of subjects who reacted to $\operatorname{Der} p$ I also reacted to Der $p$ II, potentially confounding the associations seen for both allergens to HLA-DRB1* 1 and HLA-DRB1* 1501 . Der $p$ II titres were therefore included as a covariate in the model predicting Der $p$ I titres. The association between Der $p$ I and HLA-DRB ${ }^{*} 1501$ became insignificant, and only the negative association with HLA-DRB $1{ }^{*} 01$ remained $\left(\chi^{2}{ }_{1}=7.32\right.$, $\left.P=0.0068, \sigma^{2}=0.9 \%\right)$. Similarly, when Der $p$ I titres were included as a covariate in the model predicting Der $p$ II, only the positive association with HLA-DRB1*1501 remained $\left(\chi_{1}^{2}=9.89, P=0.0017, \sigma^{2}=1.1 \%\right)$.

A test of admixture was performed, by comparing the between and within family effects of HLA-DRB1 alleles on the relevant phenotypes. ${ }^{19}$ No evidence was found for admixture with the total serum IgE levels $\left(\chi^{2}{ }_{7}=2.4\right)$, Der $p$ I titres with $\log _{\mathrm{e}} \operatorname{IgE}$ as a covariate $\left(\chi^{2}{ }_{7}=10.4\right), \operatorname{Der} p$ II titres with $\log _{\mathrm{e}} \operatorname{IgE}$ as a covariate $\left(\chi^{2}{ }_{7}=5.1\right)$ or $\mathrm{Fel} d \mathrm{I}$ titres with $\log _{\mathrm{e}} \operatorname{IgE}$ as a covariate $\left(\chi^{2}{ }_{7}=1.01\right)$. Tests of transmission disequilibrium were then performed. The number of children testable for transmission disequilibrium was 509 , so that the effective sample size was approximately halved. Nevertheless, the multi-allelic test was significantly positive for the $\operatorname{Der} p$ I titres with $\log _{\mathrm{e}} \operatorname{IgE}$ as a covariate $\left(\chi^{2}{ }_{7}=19.88, P=0.0058, \sigma^{2}=3.9 \%\right)$ and $\operatorname{Der} p$ II titres with $\log _{\mathrm{e}} \operatorname{IgE}$ as a covariate $\left(\chi^{2}{ }_{7}=15.3\right.$, $\left.P=0.032, \sigma^{2}=2.8 \%\right)$, but failed to reach significance for the total serum $\operatorname{IgE}\left(\chi_{7}^{2}=8.64, P=0.3, \sigma^{2}=1.4 \%\right)$ or for Fel $d$ I titres $\left(\chi^{2}=2.83\right)$.

\section{Discussion}

The results of the present study show strong associations between HLA-DRB1 alleles and the total serum IgE concentration and IgE titres against individual antigens. Associations were not detected with asthma, bronchial responsiveness, or peripheral blood eosinophil counts.

The results suggest that HLA-DRB1 locus accounts for 2 to $3 \%$ of the variation in specific IgE titres, and $4 \%$ of the variation in total serum IgE levels. These estimates of variation may be low if the identified HLA-DRB1 alleles do not themselves modify IgE responses, but instead are in partial linkage disequilibrium with other HLA loci that have direct effects on these traits. 
The results extend previous studies that have demonstrated HLA Class II associations with reactivity to particular antigens. A strong and consistent association has been found between a ragweed antigen (Amb a V) and HLA-DR2 (HLADRB1*1501). ${ }^{20}$ Other confirmed associations include Alt a I (from the mould Alternaria alternata) and DRB $1 * 04,{ }^{21}$ Bet $v$ I (from Birch tree pollen Betula verrucosa) and DRB3*0101, ${ }^{22,23}$ Par $o$ I (from the weed Parietaria officinalis) and DRB1*1101 and/or $1104,{ }^{24}$ and cockroach allergy and DRB1*0101 (in Hutterites) or DRB1*0102 (in African Americans). ${ }^{25}$ Many other associations have been claimed, but have not been replicated (see ${ }^{26}$ for review), perhaps as a result of small

Table 2 HLA-DRB1 allele frequencies

\begin{tabular}{lcc}
\hline $\begin{array}{l}\text { HLA-DRB1 } \\
\text { Allele }\end{array}$ & $\begin{array}{c}\text { Frequency } \% \\
\text { (all subjects) }\end{array}$ & $\begin{array}{c}\text { Frequency } \% \\
\text { (parents) }\end{array}$ \\
\hline *01 & 8.0 & 8.1 \\
*1501 & 13.5 & 14.2 \\
*03 & 13.9 & 0.5 \\
*0401 & 11.8 & 11.6 \\
*0402 & 1.2 & 1.0 \\
*0403 & 0.6 & 0.5 \\
*0404 & 3.9 & 4.3 \\
*0405 & 0.4 & 0.3 \\
*0407 & 1.0 & 0.9 \\
*0408 & 0.5 & 0.7 \\
*07 & 15.2 & 14.7 \\
*08 & 3.1 & 3.0 \\
*09 & 1.1 & 1.1 \\
*10 & 1.0 & 1.0 \\
*11 & 5.6 & 5.4 \\
*12 & 2.0 & 2.1 \\
*13 & 9.7 & 10.2 \\
*14 & 2.7 & 2.5 \\
*0103 & 2.2 & 2.1 \\
*1502, 1601, 1602 & 1.6 & 1.6 \\
unknown & 0.3 & 0.5 \\
\hline & &
\end{tabular}

sample sizes, and failure to correct for multiple comparisons or hidden admixture.

In vitro studies have shown that individual HLA-DR alleles restrict the ability of $T$ cells to respond to particular allergens which have been processed by antigen-presenting cells, ${ }^{27-29}$ so that alleles showing association to allergen reactivity in our study may be causal in the disease process.

The present study is the first to show HLA-DRB1 associations with HDM allergens. Only 14\% of subjects in the study had positive IgE titres to Fel $d$ I, limiting the power to detect association. Nevertheless, the marginal association between Fel $d$ I sensitivity and DRB1*04 is consistent with in vitro findings which have shown T cells to respond to Fel $d$ I peptides presented by DRB ${ }^{\star} 04$ positive cells. ${ }^{29}$

The results show that alleles associated with elevations of the total serum IgE were different to those associated with HDM allergens or Fel $d$ I. Associations to specific allergens or to the total serum IgE were improved when their respective confounding effects were controlled for by their inclusion as covariates. These results were consistent with hypotheses that the serum $\operatorname{IgE}$ is made up of cognate (specific) and noncognate components, ${ }^{18}$ and with previous segregation studies that have suggested that specific and total serum IgE concentrations may have some separate genetic controls ${ }^{6,7}$

In general, less than $1 \%$ of an individual's total serum IgE is made up of IgE to specific allergen ${ }^{7}$ (although the proportion may on occasion be much higher). The results therefore suggest either that an unknown antigen is driving an exceptional IgE response in an HLA-DRB ${ }^{*} 01$ restricted manner, or that the allele is in some way enhancing non-specific IgE production. Alternatively, the allele may be in linkage disequilibrium with a polymorphism in an unidentified gene which drives non-cognate $\operatorname{IgE}$ production.

Table 3 Multi-allelic tests of association and the effects of covariates

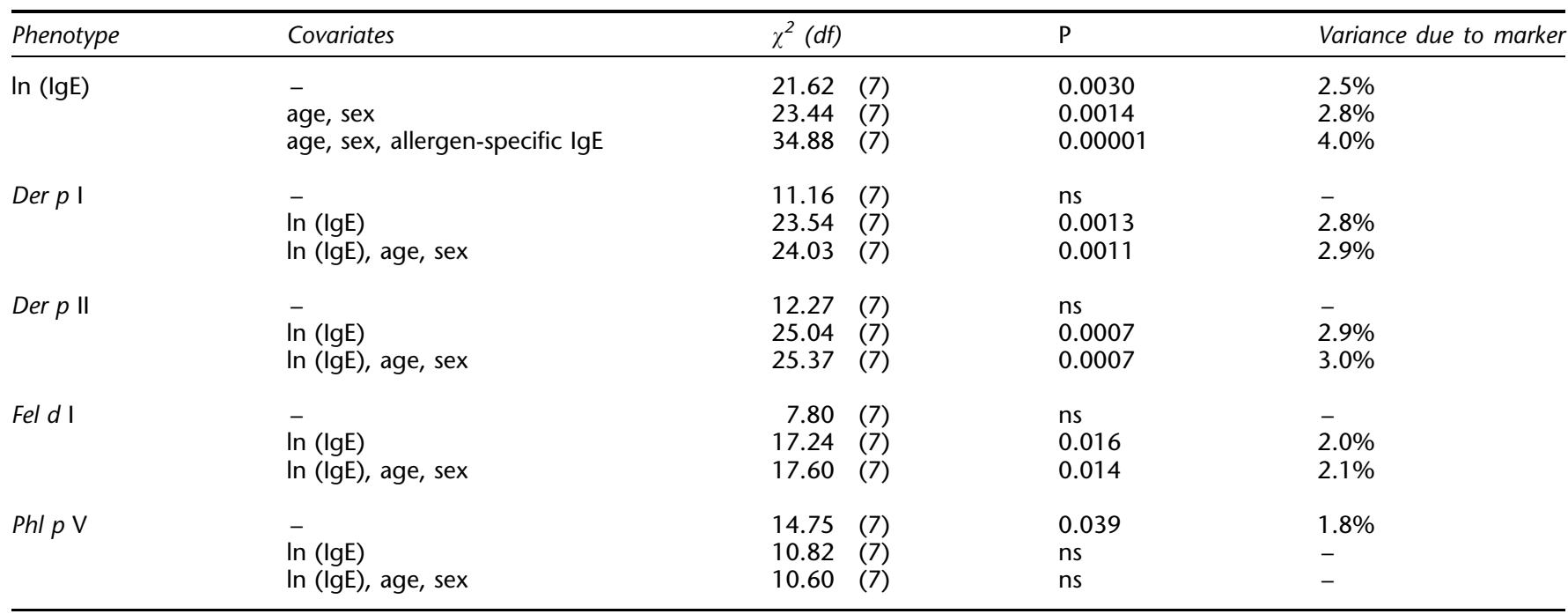


Table 4 Association of individual alleles with the total serum lgE

\begin{tabular}{|c|c|c|c|c|c|c|}
\hline Phenotype & Allele & Covariates & $\chi^{2}(d f)$ & $P$ & Direrction of association & Variance due to allele \\
\hline \multirow{2}{*}{$\ln (\lg E)$} & HLA-DRB1*03 & age, sex, allergen-specific lg $\mathrm{E}$ & 4.90 & 0.027 & positive & $0.5 \%$ \\
\hline & HLA-DRB $1 * 0401$ & age, sex, allergen-specific lgE & 6.50 & 0.011 & negative & $0.7 \%$ \\
\hline
\end{tabular}

Table 5 Association of individual alleles with lgE titres to major allergens

\begin{tabular}{|c|c|c|c|c|c|c|c|}
\hline Phenotype & Allele & Covariates & $\chi^{2}(d f)$ & & $P$ & Direction of association & Variance due to allele \\
\hline Der $p$ II & $\begin{array}{l}\text { HLA-DRB*01 } \\
\text { HLA-DRB1 }{ }^{*} 1501\end{array}$ & $\begin{array}{l}\text { age, sex, } \ln (\lg E) \\
\text { age, sex, In }(\lg E)\end{array}$ & $\begin{array}{r}7.96 \\
15.61\end{array}$ & $\begin{array}{l}(1) \\
(1)\end{array}$ & $\begin{array}{l}0.0048 \\
0.0001\end{array}$ & $\begin{array}{l}\text { negative } \\
\text { positive }\end{array}$ & $\begin{array}{l}1.1 \% \\
1.8 \%\end{array}$ \\
\hline
\end{tabular}

The use of a family-based sample and the QTDT program has allowed exploration of the effects of covariates and potential population admixture. In addition it has been possible to quantify the proportion of variance in each trait attributable to the HLA-DRB1 locus. The methods implemented in the QTDT program are therefore shown to provide a robust framework for the investigation of allelic associations to complex quantitative traits.

The study has differed from previous investigations of HLA-DRB1 because it was able to investigate the effects of the locus on multiple phenotypes. Genetic linkage to the MHC region has been previously demonstrated with asthma, $^{10,12}$ total serum IgE levels, ${ }^{12}$ eosinophil counts ${ }^{9}$ and specific IgE levels. ${ }^{11}$ The present study is consistent with the findings of linkage to specific IgE levels ${ }^{11}$ and to total serum IgE levels. ${ }^{12}$ However, the absence of association between asthma or eosinophilia and HLA-DRB1 suggests that other loci from the MHC or its surrounds should now be investigated.

The Tumour Necrosis Factor complex within the MHC contains polymorphisms which are associated with variation in the expression of TNF-alpha and the presence of asthma. ${ }^{30-32}$ The relative risk of TNF alleles on asthma ${ }^{30}$ is of the order of 2, and it is not clear that this is sufficient to account for the strength of genetic linkage observed to asthma in Hutterites ${ }^{10}$ or German schoolchildren. ${ }^{12}$

Other polymorphisms in the Class II region, such as those in C4, have not been investigated for a role in asthma. Many other genes from the Class I and other regions of the MHC may also have important effects on asthma or atopic responses, but these have not yet been adequately investigated. Nevertheless, the clear and limited role for the HLADRB1 locus shown by our results may be used as a first step in the detailed investigation of a region which has major influences on asthma susceptibility.

\section{Acknowledgments}

We would like to thank the people of Busselton for their participation in the study, and our many colleagues who have helped in the field testing of the population. The study was funded by the Wellcome Trust and the National Asthma Campaign.

\section{References}

1 Strachan DP, Anderson HR, Limb ES, O'Neill A, Wells N: A national survey of asthma prevalence, severity, and treatment in Great Britain. Arch Dis Child 1994; 70: 174-178.

2 Duffy DL, Martin NG, Battistutta D, Hopper JL, Mathews JD: Genetics of asthma and hay fever in Australian twins. Am Rev Respir Dis 1990; 142: 1351-1358.

3 Ober C, Moffatt MF: Contributing factors to the pathobiology. The genetics of asthma [In Process Citation]. Clin Chest Med 2000; 21: $245-261$.

4 Sears MR, Herbison GP, Holdaway MD, Hewitt CJ, Flannery EM, Silva PA: The relative risks of sensitivity to grass pollen, house dust mite and cat dander in the development of childhood asthma. Clin Allergy 1989; 18: 419-424.

5 Cookson WOCM, De Klerk NH, Ryan GR, James AL, Musk AW: Relative risks of bronchial hyper-responsiveness associated with skin-prick test responses to common antigens in young adults. Clin Exp Allergy 1991; 21: 473 - 479.

6 Dizier MH, James A, Faux J et al: Segregation analysis of the specific response to allergens: a recessive major gene controls the specific IgE response to Timothy grass pollen. Genet Epidemiol 1999; 16: $305-315$.

7 Palmer LJ, Burton PR, Faux JA, James AL, Musk AW, Cookson WO: Independent inheritance of serum immunoglobulin $\mathrm{E}$ concentrations and airway responsiveness. Am J Respir Crit Care Med 2000; 161: 1836-1843.

8 Cookson W: The alliance of genes and environment in asthma and allergy. Nature 1999; 402 (Suppl): B5-B11. 
9 Daniels SE, Bhattacharrya S, James A et al: A genome-wide search for quantitative trait loci underlying asthma. Nature 1996; 383: $247-250$.

10 Ober C, Cox NJ, Abney M et al: Genome-wide search for asthma susceptibility loci in a founder population. The Collaborative Study on the Genetics of Asthma. Hum Mol Genet 1998; 7: 1393 1398.

11 Hizawa N, Freidhoff L, Chiu Y et al: Genetic regulation of Dermatophagoides pteronyssinus-specific IgE responsiveness: a genome-wide multipoint linkage analysis in families recruited through 2 asthmatic sibs. Collaborative Study on the Genetics of Asthma (CSGA). J Allergy Clin Immunol 1998; 102: 436-442.

12 Wjst M, Fischer G, Immervoll T et al: A genome-wide search for linkage to asthma. German Asthma Genetics Group. Genomics 1999; 58: $1-8$.

13 Hill MR, James AL, Faux JA et al: FceRI- $\beta$ polymorphism and risk of atopy in a general population sample. $B r$ Med $J$ 1995; 311: $776-779$.

14 Yan K, Salome C, Woolcock AJ: Rapid method for measurement of bronchial responsiveness. Thorax 1983; 38: 760- 765 .

15 Wordsworth BP, Allsopp CE, Young RP, Bell JI: HLA-DR typing using DNA amplification by the polymerase chain reaction and sequential hybridization to sequence-specific oligonucleotide probes. Immunogenetics 1990; 32: 413-418.

16 Moffatt MF, James A, Ryan G, Musk AW, Cookson WO: Extended tumour necrosis factor/HLA-DR haplotypes and asthma in an Australian population sample. Thorax 1999; 54: 757-761.

17 Abecasis GR, Cardon LR, Cookson WO: A general test of association for quantitative traits in nuclear families. $\mathrm{Am} \mathrm{J}$ Hum Genet 2000; 66: 279-292.

18 Marsh DG, Bias WB, Ishizaka K: Genetic control of basal serum immunoglobulin $\mathrm{E}$ level and its effect on specific reaginic sensitivity. Proc Natl Acad Sci USA 1974; 71: 3588 - 3592.

19 Fulker DW, Cherny SS, Sham PC, Hewitt JK: Combined linkage and association sib-pair analysis for quantitative traits. $\mathrm{Am} \mathrm{J}$ Hum Genet 1999; 64: 259-267.

20 Marsh DG, Meyers DA, Bias WB: The epidemiology and genetics of atopic allergy. New Engl Med 1981; 305: 1551-1559.

21 Young RP, Dekker JW, Wordsworth BP, Cookson WOCM: HLADR and HLA-DP genotypes and Immunoglobulin E responses to common major allergens. Clin Exp Allergy 1994; 24: 431 - 439.
22 Fischer GF, Pickl WF, Fae I et al: Association between IgE response against Bet $\mathrm{v} \mathrm{I}$, the major allergen of birch pollen, and HLA-DRB alleles. Hum Immunol 1992; 33: 259-265.

23 Sparholt SH, Georgsen J, Madsen HO, Svendsen UG, Schou C: Association between HLA-DRB3 ${ }^{*} 0101$ and immunoglobulin-E responsiveness to Bet v I. Hum Immunol 1994; 39: 76 - 78 .

24 D'Amato M, Scotto d'Abusco A, Maggi E et al: Association of responsiveness to the major pollen allergen of Parietaria officinalis with HLA-DRB1* alleles: a multicenter study. Hum Immunol 1996; 46: 100-106.

25 Donfack J, Tsalenko A, Hoki DM et al: HLA-DRB1*01 alleles are associated with sensitization to cockroach allergens. J Allergy Clin Immunol 2000; 105: 960-966.

26 Moffatt MF, Cookson WO: The genetics of specific allergy. Monogr Allergy 1996; 33: 71-96.

27 Higgins J, Thorpe C, Hayball J, O'Hehir R, Lamb J: Overlapping T-cell epitopes in the group I allergen of Dermatophagoides species restricted by HLA-DP and HLA-DR class II molecules. $J$ Allergy Clin Immunol 1994; 93: 891 - 899.

28 Okano M, Nagano T, Nakada M et al: Epitope analysis of HLADR-restricted helper T-cell responses to Der $\mathrm{p}$ II, a major allergen molecule of Dermatophagoides pteronyssinus. Allergy 1996; 51: $29-35$.

29 Haselden BM, Kay AB, Larche M: Immunoglobulin E-independent major histocompatibility complex-restricted T cell peptide epitope-induced late asthmatic reactions. J Exp Med 1999; 189: $1885-1894$.

30 Moffatt MF, Cookson WO: Tumour necrosis factor haplotypes and asthma. Hum Mol Genet 1997; 6: 551-554.

31 Li Kam Wa TC, Mansur AH, Britton J et al: Association between -308 tumour necrosis factor promoter polymorphism and bronchial hyperreactivity in asthma. Clin Exp Allergy 1999; 29: $1204-1208$.

32 Chagani T, Pare PD, Zhu S et al: Prevalence of tumor necrosis factor-alpha and angiotensin converting enzyme polymorphisms in mild/moderate and fatal/near-fatal asthma. Am J Respir Crit Care Med 1999; 160: 278-282. 